\title{
A Reliable and Valid Survey to Predict a Patient's Gagging Intensity
}

\author{
Casey M. Hearing, ${ }^{1, a}$, Rebecca H. Bind ${ }^{1, a}$, Michael J. Tabacco², Robert M. Hallock ${ }^{1}$ \\ ${ }^{1}$ Neuroscience program, Skidmore College, Saratoga Springs, New York, USA. \\ ${ }^{2}$ Department of Endodontic, Prosthodontics, and Operative Dentistry, University of Maryland, Baltimore, Maryland, USA.

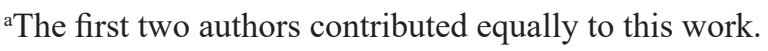

\author{
Corresponding Author: \\ Robert M. Hallock \\ 815 N Broadway, Saratoga Springs \\ New York 12866 \\ USA \\ Phone: (518) 5805740 \\ Fax: (518) 5805319 \\ E-mail: rhallock@skidmore.edu
}

\section{ABSTRACT}

Objectives: The aim of this study was to devise a reliable and valid survey to predict the intensity of someone's gag reflex. Material and Methods: A 10-question Predictive Gagging Survey was created, refined, and tested on 59 undergraduate participants. The questions focused on risk factors and experiences that would indicate the presence and strength of someone's gag reflex. Reliability was assessed by administering the survey to a group of 17 participants twice, with 3 weeks separating the two administrations. Finally, the survey was given to 25 dental patients. In these cases, patients completed an informed consent form, filled out the survey, and then had a maxillary impression taken while their gagging response was quantified from 1 to 5 on the Fiske and Dickinson Gagging Intensity Index.

Results: There was a moderate positive correlation between the Predictive Gagging Survey and Fiske and Dickinson's Gagging Severity Index, $r=+0.64$, demonstrating the survey's validity. Furthermore, the test-retest reliability was $r=+0.96$, demonstrating the survey's reliability.

Conclusions: The Predictive Gagging Survey is a 10-question survey about gag-related experiences and behaviours. We established that it is a reliable and valid method to assess the strength of someone's gag reflex.

Keywords: dentistry; gagging; surveys.

\author{
Accepted for publication: 1 April 2014 \\ To cite this article: \\ Hearing CM, Bind RH, Tabacco MJ, Hallock RM. A Reliable and Valid Survey to Predict a Patient's Gagging Intensity. \\ J Oral Maxillofac Res 2014;5(2):e3 \\ URL: http://www.ejomr.org/JOMR/archives/2014/2/e3/v5n2e3ht.pdf \\ doi: $10.5037 /$ jomr.2014.5203
}




\section{INTRODUCTION}

The gag reflex is a natural physiological process that functions to protect the mouth and the pharynx $[1,2]$. It is typically a reaction to some perceived unpleasant sensory input or a psychological trigger [3]. The process of gagging takes place following an internal or external event which induces rapid contractions of the pharynx in order to protect the airway [3]. Sometimes, however, one's gag reflex can be oversensitive and impede important activities, such as going to the dentist [2].

Nearly $74 \%$ of people possess a gag reflex, and it ranges in intensity from minor to strong enough to interfere with daily activities of life [4]. Major factors contributing to intense gag reflexes can be divided into two categories: somatogenic and psychogenic $[\underline{3}, \underline{5}]$. Somatogenic events leading to gagging include sensory stimuli of any kind while psychogenic influences only require a psychological event [6].

One very common trigger for gagging is dental procedures, as gagging can be prompted from the procedure itself, or from the anxiety and negative expectations of an office visit [2]. Additionally, gagging can develop to the point of making proper treatment nearly impossible. The anxiety that develops from gagging sensitivity often becomes a negative feedback loop - as a result of gagging, patients may avoid going to the dentist, creating greater dental problems, and thus potentially more gagging opportunities when a dental visit becomes necessary [7].

As a result of the varying intensities of patient's gag reflexes, Fiske and Dickinson [ $[\overline{]}]$ developed a Gagging Severity Index (GSI) that ranks a patient's gag sensitivity on a scale from 1 (least severe) to 5 (most severe). The objective of the GSI was to calculate gag sensitivity in such a way that it could be universally scored among dental professionals. Ideally, this scale would be able to facilitate tailoring dental treatment for subsets of patients with different gagging intensities.

To assess the expected gag-intensity of a dental patient, an interview may allow dentists to get an idea of the patient's gag history [9]. Further, a dentist may map out the trigger points of the gag reflex in the oral cavity before dental treatment, and this can subsequently help the dentist avoid these trigger points during the course of treatment [3] Our goal was to develop a short questionnaire that predicts gag sensitivities. With this survey, oral health professionals can assess the intensity of a patient's gag response prior to treatment in order to minimize negative experiences and maximize treatment strategies for those patients most at risk of having a severe gag reflex.

\section{MATERIAL AND METHODS}

A questionnaire was developed that explored various risk factors for a gag reflex. The questionnaire was in the English language and administered to undergraduate Psychology and Neuroscience students at Skidmore College in New York State, United States of America. The survey was first given to a focus group of eight undergraduate students. These focus-study participants did not participate in subsequent testing. Questions and options were thoroughly discussed and feedback was incorporated into the questionnaire. Next, the revised survey was given to three separate undergraduate classes ( $\mathrm{n}=51$ participants) in the neuroscience and psychology departments, with 1 week separating each of the three administrations. The questions and scoring were modified after each class until the survey produced clear, unambiguous questions, with a wide range of final scores that fit a normal bell-shaped distribution. In a fourth class ( $\mathrm{n}=17$ participants), the survey was administered and then re-administered 3 weeks later. The test-retest reliability was assessed with a Pearson product-moment correlation.

Finally, the survey was administered to 25 randomly sampled dentistry patients of author MJT who were undergoing dental impressions. Dentistry patients filled out an informed consent form, completed the Predictive Gagging Survey, and then underwent a maxillary dental impression. The surveys from two patients were excluded because their surveys were incomplete or improperly filled out. Thus, the analyses reflect data from 23 patients.

MJT, who was blind to the responses on a given patient's survey, took the dental impression and measured the patient's gag response according to the GSI. Scores on the survey and GSI were compared using a Pearson product-moment correlation. A copy of the questionnaire, with scoring instructions, is included in Appendix A. Undergraduate students received extra credit in their courses for participation and dental patients were not compensated for participation. All procedures were approved by the Skidmore College Psychological Review Board (New York, USA).

\section{Statistical analysis}

Pearson product-moment correlation was used for 
the test-retest reliability assessment. Statistics were performed using IBM SPSS Statistics 20.0 (IBM, Armonk, New York, USA). Parametric data were expressed as mean and standard deviation (M [SD]). Statistical significance level was defined at $\mathrm{P}=0.05$.

\section{RESULTS}

A Pearson product-moment correlation revealed that there was a significant positive correlation between the patient's score on the GSI and the survey we administered, $\mathrm{r}(21)=+0.641, \mathrm{n}=23, \mathrm{P}=0.002$, two tails. As severity of the gag response increased according to the GSI, the score on the Predictive Gagging Survey increased (Figure 1). The equation of a linear regression line is: $y=0.1808 x+0.8105$. The mean score on the survey administered to dental patients was $4.05(3.09)$ while the mean score on the GSI was $1.6(0.94)$. Scores above 7 on the Predictive Gagging Survey defined the upper $25 \%$ of scores.
All of these scores corresponded to a moderate to severe gag reflex in response to a dental impression (Table 1). Lastly, in a measure of test-retest reliability, a Pearson product-moment correlation revealed a significant positive correlation between the first and second administrations of the survey, $\mathrm{r}(15)=0.962$, $\mathrm{n}=17, \mathrm{P}<0.0001$, two tails.

\section{DISCUSSION}

The results of the current study showed that the severity of the gag reflex can be predicted by a short survey, the Predictive Gagging Survey. The survey is valid: there is a moderately positive correlation between the score on our survey and the GSI. Furthermore, the survey is reliable: scores are very consistent over time. The survey takes no more than 5 minutes for a patient to complete, and it is also quick and easy for a dental health professional to score.

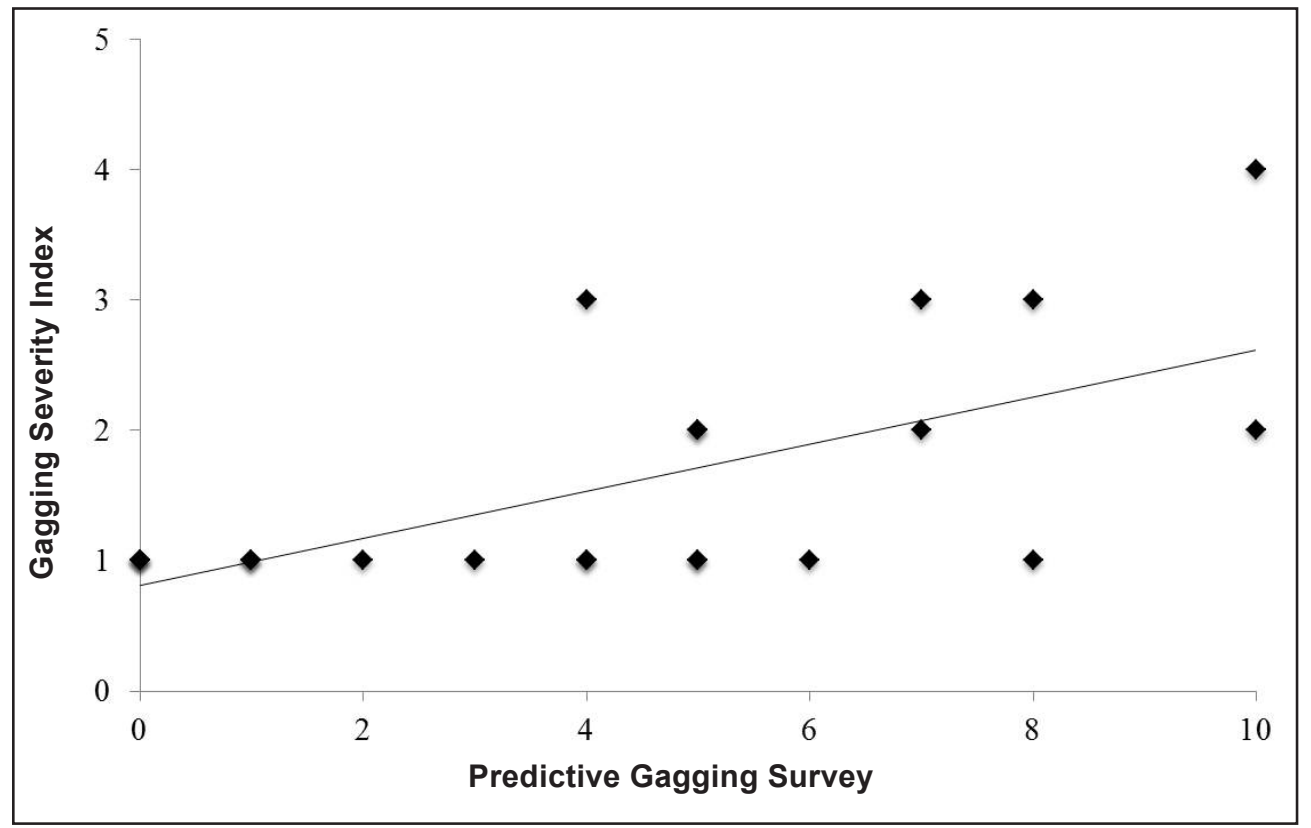

Figure 1. A scatterplot of patients scores on the Predictive Gagging Survey (abscissa) plotted against scores on Gagging Severity Index (ordinate). Pearson's $r=0.64, \mathrm{P}=0.002$.

Table 1. Definition of each GSI score and percentage of patients assigned each score

\begin{tabular}{c|c|c}
\hline $\begin{array}{c}\text { Dickinson and Fiske Gagging } \\
\text { Severity Index grades }\end{array}$ & Definition and characteristics of grade of reflex & $\begin{array}{c}\text { Percent of patients with score } \\
\text { in present study as assessed by MJT }\end{array}$ \\
\hline Grade I & Very mild, occasional and controlled by the patient & 65 \\
\hline Grade II & $\begin{array}{c}\text { Moderate, control is required by the patient with } \\
\text { reassurance from the dental team }\end{array}$ & 15 \\
\hline Grade III & Moderate, consistent and limits treatment options & 5 \\
\hline Grade IV & Severe and treatment is impossible & 0 \\
\hline Grade V & $\begin{array}{c}\text { Very severe, affecting patient behaviour and dental } \\
\text { attendance and making treatment impossible }\end{array}$ \\
\hline
\end{tabular}


There are several other surveys meant to assess various aspects of the gagging reflex. The Gagging Assessment Scale (GAS) asks the patient how they feel in four situations, ranging from personal dental care (brushing ones teeth) to undergoing dental treatment in the back of the mouth [10]. The GAS asks the patients to score how nauseated they would feel in each situation on a scale from 1 (no nausea whatsoever), to 5 (experiencing actual throat spasms and occasionally throwing up). Although the GAS is positively correlated with patient anxiety levels $[\underline{10}]$, it does not assess the severity of a gag reflex during dental procedures. The 5-level Classification of Gagging Problem (CGP) assesses the severity of a patient's gagging reflex and classifies patients into those who can successfully be treated for desensitization of the gag reflex within one year and those who cannot [11]. Patients who scored a 1 or 2 (normal but not desensitized gagging or mild gagging) were desensitized within a year of treatment. Patients scoring a 3, 4, or 5 (moderate, severe, and very severe gagging) were not able to be desensitized within a year. While the CGP is effective at classifying patients, it requires that the patient be gagged in order to determine the intensity of their gagging reflex.

Finally, the Gagging Problem Assessment (GPA) is a 32 question assessment for the patient that asks about their general medical conditions and dental anxiety, coupled with a 20 question diagnostic test completed by the dentist to assess the severity of the gag reflex [12]. This survey identifies patients with a significant gagging problem, but again relies on invasive prob. There is also a nine question version of the GPA that can be completed by the patient that is not complimented by invasive probing, and this has been shown to be reliable and valid [13-15]. The shortened GPA contains questions that have patients estimate the level of gagging induced by 'feeling a mirror between posterior teeth', 'taking an impression of the upper jaw', and 'taking an impression of the lower jaw'. The questions on the shortened GPA pertain almost exclusively to experiences in dental offices. Our Predictive Gagging Survey is superior in that it does not require the dentist to gag the patient, nor does it require experience from specific dental procedures.

Our study is limited for two principle reasons. First, we have a limited sample of patients who took our survey and then received a dental implant and had the intensity of their gag reflex assessed. In our sample, there were no patients whose gag intensity was very severe and one patient who was rated as severe. These ratings corresponded to grades $\mathrm{V}$ and IV on the Dickinson and Fiske GSI respectively. Despite this, there were 14 patients in our sample who had a very mild or moderate gag reflex (grades I through III). Second, we did not separately measure the gag responses of men and women. This could have been an interesting addition to see if there was as sex difference among the 59 undergraduate participants who took our survey, or if there was a sex difference in the gag response among the dental patients. However, one study found no sex difference in gagging severity [16].

The Predictive Gagging Survey is novel in that previously designed measures to assess the gag reflex require an activation of the gag reflex. For example, mapping out the trigger points in the oral cavity may be important to find specific trigger points of the gag reflex [3], but this mapping procedure may be counterproductive in that patients with a severe gag reflex may form a negative association with the dental experience even before any treatment.

Our survey may allow professionals to identify gagging patients a priori, and then administer treatments preemptively before dental treatment. Using the linear regression equation from the bestfit line through the data, a score of 2 on the GSI (a mild gag reflex that requires reassurance from the dental team) corresponds with a score of 6.58 on the Predictive Gagging Survey. Thus, we recommend that anyone who scores a 7 or greater on the Predictive Gagging Survey may benefit from treatment methods to control the gag reflex. This score corresponds to the upper $25 \%$ of respondents.

Numerous methods have been proposed to alleviate the gag reflex in patients undergoing dental procedures. These methods include the use of local or general anaesthesia [17-19] and acupuncture $[\underline{8}, \underline{20}, \underline{21}]$. Relaxation techniques $[\underline{22}, \underline{23}]$ and even diverting attention [24] can also ameliorate gagging. A case report found that intranasal midazolam, a benzodiazepine, reduced the patient's experience of the gag reflex [25]. Additionally, some case reports show that using chemical stimulation of the oral palate with a sodium chloride solution can temporarily reduce the gag reflex [26-28], although a controlled study failed to find a significant effect of table salt in reducing the gag reflex [13]. It may also be interesting to examine whether a stronger gag reflex is correlated with increased orofacial pain that is itself related to third molar extraction [29]. Identifying patients most at risk for a gag reflex that may limit or prevent dental work may allow oral health professionals to preemptively administer these treatments, thus alleviating the patient undo stress associated with dental visits. 


\section{CONCLUSIONS}

The Predictive Gagging Survey is a novel method to assess the strength of someone's gag reflex. The survey is a single-page 10-question survey about gagrelated experiences and behaviours. We found that it accurately predicts the severity of a patient's gagging reflex, and that it has high test-retest reliability.

\section{ACKNOWLEDGMENTS AND DISCLOSURE STATEMENTS}

The authors confirm that they have no conflict of interest with respect to the material presented in this paper.

\section{REFERENCES}

1. Conny DJ, Tedesco LA. The gagging problem in prosthodontic treatment. Part I: description and causes. J Prosthet Dent. 1983 May;49(5):601-6. [Medline: 6343586] [doi: 10.1016/0022-3913(83)90381-5]

2. Dickinson CM, Fiske J. A review of gagging problems in dentistry: I. Aetiology and classification. Dent Update. 2005 Jan-Feb;32(1):26-8, 31-2. Review. [Medline: 15739661]

3. Kumar S, Satheesh P, Savadi RC. Gagging. N Y State Dent J. 2011 Jun-Jul;77(4):22-7. [Medline: 21894827]

4. Davies AE, Kidd D, Stone SP, MacMahon J. Pharyngeal sensation and gag reflex in healthy subjects. Lancet. 1995 Feb 25;345(8948):487-8. [Medline: 7861875] [doi: 10.1016/S0140-6736(95)90584-7]

5. Saunders RM, Cameron J. Psychogenic gagging: identification and treatment recommendations. Compend Contin Educ Dent. 1997 May;18(5):430-3, 436, 438 passim. [Medline: 9533356]

6. Bassi GS, Humphris GM, Longman LP. The etiology and management of gagging: a review of the literature. J Prosthet Dent. 2004 May;91(5):459-67. Review. [Medline: 15153854] [doi: 10.1016/j.prosdent.2004.02.018]

7. Hainsworth JM, Hill KB, Rice A, Fairbrother KJ. Psychosocial characteristics of adults who experience difficulties with retching. J Dent. 2008 Jul;36(7):494-9. Epub 2008 May 29. [Medline: 18513848] [doi: $10.1016 /$ j.jdent.2008.03.011]

8. Fiske J, Dickinson C. The role of acupuncture in controlling the gagging reflex using a review of ten cases. Br Dent J. 2001 Jun 9;190(11):611-3. [Medline: 11441900 ] [doi: $10.1038 /$ sj.bdj.4801053]

9. Dickinson CM, Fiske J. A review of gagging problems in dentistry: 2. Clinical assessment and management. Dent Update. 2005 Mar;32(2):74-6, 78-80. [Medline: 15819150]

10. Winocur E, Uziel N, Lisha T, Goldsmith C, Eli I. Self-reported bruxism - associations with perceived stress, motivation for control, dental anxiety and gagging. J Oral Rehabil. 2011 Jan;38(1):3-11. [Medline: 20557433] [doi: 10.1111/j.1365-2842.2010.02118.x]

11. Saita N, Fukuda K, Koukita Y, Ichinohe T, Yamashita S. Relationship between gagging severity and its management in dentistry. J Oral Rehabil. 2013 Feb;40(2):106-11. Epub 2012 Dec 10. [Medline: 23231041] [doi: 10.1111/joor.12014]

12. Van Linden van den Heuvell GF, Ter Pelkwijk BJ, Stegenga B. Development of the Gagging Problem Assessment: a pilot study. J Oral Rehabil. 2008 Mar;35(3):196-202. [Medline: 18254797] [doi: 10.1111/j.1365-2842.2007.01774.x]

13. Akarslan ZZ, Yıldırım Biçer AZ. Influence of gag reflex on dental attendance, dental anxiety, self-reported temporomandibular disorders and prosthetic restorations. J Oral Rehabil. 2013 Dec;40(12):932-9. Epub 2013 Oct 11. [Medline: 24118087] [doi: 10.1111/joor.12106]

14. Akarslan ZZ, Biçer AZ. Utility of the gagging problem assessment questionnaire in assessing patient sensitivity to dental treatments. J Oral Rehabil. 2012 Dec;39(12):948-55. Epub 2012 May 29. [Medline: 22642624] [doi: $10.1111 / j .1365-2842.2012 .02321 . x]$

15. Akarslan ZZ, Erten H. Reliability and validity of the Turkish version of the shorter form of the gagging problem assessment questionnaire. J Oral Rehabil. 2010 Jan;37(1):21-5. [Medline: 20409127] [doi: 10.1111/j.1365-2842.2009.02029.x]

16. Rosted P, Bundgaard M, Fiske J, Pedersen AM. The use of acupuncture in controlling the gag reflex in patients requiring an upper alginate impression: an audit. Br Dent J. 2006 Dec 9;201(11):721-5; discussion 715. [Medline: 17159959 ]

17. Chidiac JJ, Chamseddine L, Bellos G. Gagging prevention using nitrous oxide or table salt: a comparative pilot study. Int J Prosthodont. 2001 Jul-Aug;14(4):364-6. [Medline: 11508093]

18. Hallonsten AL, Koch G, Schröder U. Nitrous oxide-oxygen sedation in dental care. Community Dent Oral Epidemiol. 1983 Dec;11(6):347-55. [Medline: 6580999] [doi: 10.1111/j.1600-0528.1983.tb01390.x]

19. Hattab FN, Al-Omari MA, Al-Dwairi ZN. Management of a patient's gag reflex in making an irreversible hydrocolloid impression. J Prosthet Dent. 1999 Mar;81(3):369. Erratum in: J Prosthet Dent. 2005 May;93(5):499. Al-Duwayri, ZN [corrected to Al-Dwairi ZN]. [Medline: 10050127] [doi: 10.1016/S0022-3913(99)70282-9]

20. Sari E, Sari T. The role of acupuncture in the treatment of orthodontic patients with a gagging reflex: a pilot study. Br Dent J. 2010 May 22;208(10):E19. [Medline: 20489741] [doi: 10.1038/sj.bdj.2010.483] 
21. Thayer ML. The use of acupuncture in dentistry. Dent Update. 2007 May;34(4):244-6, 249-50. [Medline: 17580824]

22. Barsby MJ. The use of hypnosis in the management of 'gagging' and intolerance to dentures. Br Dent J. 1994 Feb 5;176(3):97-102. [Medline: 7599007] [doi: 10.1038/sj.bdj.4808380]

23. Muir JD, Calvert EJ. Vomiting during the taking of dental impressions. Two case reports of the use of psychological techniques. Br Dent J. 1988 Aug 20;165(4):139-41. [Medline: 3048344] [doi: 10.1038/sj.bdj.4806525]

24. Kovats JJ. Clinical evaluation of the gagging denture patient. J Prosthet Dent. 1971 Jun;25(6):613-9. [Medline: 4929959]

25. Malkoc MA, Demir N, Ileri Z, Erdur A, Apiliogullari S. Intranasal midazolam may prevent gagging reflex: a case report. J Oral Maxillofac Res. 2013 Oct 1;4(3):e5. eCollection 2013. URL: http://www.ejomr.org/JOMR/ archives/2013/3/e5/v4n3e5ht.htm [Medline: 24422038] [PMC free article: 3887572] [doi: 10.5037/jomr.2013.4305]

26. Eichhold W, Hays L, O’Brien R. Gagging: the preventive effect of table salt. Ohio Dent J. 1987 Summer;61(7):63-4. [Medline: 3476882]

27. Snodgrass KR, Klenk WA. The effects of sodium chloride on the reduction of the gag reflex. W V Dent J. 1988 Oct;62(4):16-7. [Medline: 3269107$]$

28. Friedman MH, Weintraub MI. Temporary elimination of gag reflex for dental procedures. J Prosthet Dent. 1995 Mar;73(3):319. [Medline: 7760285] [doi: 10.1016/S0022-3913(05)80213-6]

29. Macfarlane TV, Blinkhorn AS, Stevenson LJ, Coulthard P. Third molar removal and orofacial pain: a populationbased survey. J Oral Maxillofac Res. 2010 Oct 1;1(3):e4. eCollection 2010. URL: http://www.ejomr.org/JOMR/ archives/2010/3/e4/e4ht.htm [Medline: 24421974] [PMC free article: 3886054] [doi: 10.5037/jomr.2010.1304]

\section{To cite this article:}

Hearing CM, Bind RH, Tabacco MJ, Hallock RM. A Reliable and Valid Survey to Predict a Patient's Gagging Intensity.

J Oral Maxillofac Res 2014;5(2):e3

URL: http://www.ejomr.org/JOMR/archives/2014/2/e3/v5n2e3ht.pdf

doi: $10.5037 /$ jomr.2014.5203

Copyright (C) Hearing CM, Bind RH, Tabacco MJ, Hallock RM. Published in the JOURNAL OF ORAL \& MAXILLOFACIAL RESEARCH (http://www.ejomr.org), 1 July 2014.

This is an open-access article, first published in the JOURNAL OF ORAL \& MAXILLOFACIAL RESEARCH, distributed under the terms of the Creative Commons Attribution-Noncommercial-No Derivative Works 3.0 Unported License, which permits unrestricted non-commercial use, distribution, and reproduction in any medium, provided the original work and is properly cited. The copyright, license information and link to the original publication on (http://www.ejomr.org) must be included. 


\section{APPENDIX A.}

Patient \#

The gag reflex is a contraction of the muscles of the pharyngeal sphincter (upper oesophagus or throat). The gag reflex is a natural protective measure of the body to protect an airway from blocking and remove material from the throat and upper gastrointestinal tract (Fiske \& Dickinson, 2001). Although the gag reflex typically serves this protective function, a strong gag reflex may impact daily life.

For the following questions, please use the scale of 1-7, in which 1 is the least severe and 7 is the most.

1. Do you have a gag reflex? YES/NO

2. How strong would you say your gag reflex is? Please circle the corresponding number on the following scale.

$\begin{array}{lllllll}1 & 2 & 3 & 4 & 5 & 6 & 7\end{array}$

Not strong at all------------moderately strong----------------very strong

3. Have you ever had a negative incident with gagging? YES/NO

4. Have you ever gagged at a dentist/orthodontist office before? YES/NO

5. Please circle any of the following experiences that have caused you to gag:
Routing teeth-cleaning
Cavity filling
Root canal
Dental x-ray
Dental impression
Other orthodontic work

Other dental work

6. When you are going to the dentist, how much stress (if any) do you experience that is related to your gag reflex? Please circle the corresponding number on the following scale.

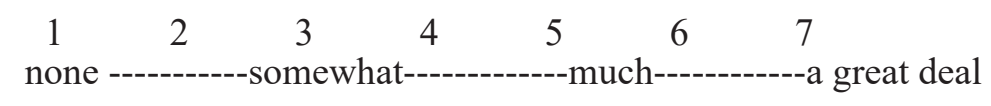

7. Have daily activities, like brushing or flossing your teeth, ever made you gag? YES/NO

How often are these occurrences?

$\begin{array}{ccccccc}1 & 2 & 3 & 4 & 5 & 6 & 7 \\ \text { never ------------seldom------------sometimes-----------often }\end{array}$

8. Do you ever worry that daily activities other than brushing or flossing your teeth will cause you to gag? YES/NO

9. Does coughing ever cause you to gag? YES/NO

10. Have you ever gagged while trying to swallow pills? YES/NO

\section{Survey Scoring}

1. yes $=1$, no $=0$

2. $1-2=0,3-5=1,6-7=2$

3. yes $=1$, no $=0$

4. yes $=1$, no $=0$

5. 1 point for each item circled

6. $1-2=0,3-5=1,6-7=2$

7. yes $=1$, no $=0 / 1-2=0,3-5=1,6-7=2$

8. yes $=1$, no $=0$

9. yes $=1$, no $=0$

10 . yes $=1$, no $=0$ 